OPEN ACCESS

Edited by:

Andreas Beilhack,

Julius Maximilian University of

Würzburg, Germany

Reviewed by:

Ying-Jun Chang,

Peking University People's Hospital,

China

Tomomi Toubai,

Yamagata University, Japan

*Correspondence:

Giuseppe Lia

lia.giuseppe@gmail.com

Specialty section:

This article was submitted to Alloimmunity and Transplantation,

a section of the journal

Frontiers in Immunology

Received: 22 December 2020 Accepted: 04 May 2021

Published: 19 May 2021

Citation:

Lia G, Giaccone L, Leone S and Bruno B (2021) Biomarkers for Early Complications of Endothelial Origin After Allogeneic Hematopoietic Stem Cell Transplantation: Do They Have a Potential Clinical Role?

Front. Immunol. 12:641427. doi: 10.3389/fimmu.2021.641427

\section{Biomarkers for Early Complications of Endothelial Origin After Allogeneic Hematopoietic Stem Cell Transplantation: Do They Have a Potential Clinical Role?}

\author{
Giuseppe Lia ${ }^{1,2 *}$, Luisa Giaccone ${ }^{1,2}$, Sarah Leone $^{3}$ and Benedetto Bruno ${ }^{2,4}$ \\ 1 Stem Cell Transplant Program, Department of Oncology, A.O.U. Città della Salute e della Scienza di Torino, Torino, Italy, \\ ${ }^{2}$ Department of Molecular Biotechnology and Health Sciences, University of Torino, Torino, Italy, ${ }^{3}$ Department of Internal \\ Medicine, New York University Grossman School of Medicine, New York, NY, United States, ${ }^{4}$ Division of Hematology and \\ Medical Oncology, New York University Grossman School of Medicine, Perlmutter Cancer Center, New York University \\ Langone Health, New York, NY, United States
}

Endothelial cell (EC) dysfunction causes a number of early and life-threatening post hematopoietic stem cell transplant $(\mathrm{HCT})$ complications that result in a rapid clinical decline. The main early complications are graft-vs.-host disease (GVHD), transplant associated thrombotic microangiopathy (TA-TMA), and sinusoidal obstruction syndrome (SOS). Post-HCT endothelial dysfunction occurs as a result of chemotherapy, infections, and allogeneic reactivity. Despite major advances in transplant immunology and improvements in supportive care medicine, these complications represent a major obstacle for successful HCT. In recent years, different biomarkers have been investigated for early detection of post-transplant endothelial cell dysfunction, but few have been validated. In this review we will define GVHD, TA-TMA and SOS, summarize the current data available in HCT biomarker research and identify promising biomarkers for detection and diagnosis of early HCT complications.

Keywords: HCT, endothelial dysfunction, SOS, GvHD, TA-TMA, biomarkers

\section{INTRODUCTION}

Hematopoietic cell transplantation (HCT) is indicated in a broad range of diseases, most frequently acute leukaemia and myelodysplastic syndromes (1). Despite the advances in hematopoietic stem cell transplants, it remains a high risk procedure that is limited by potentially life-threatening complications (2).

Early (or short-term) post-HCT complications typically occurred within the first 100 days postHCT. Most complications (e.g. mucositis and sepsis) are caused by infections. They derived from toxicity of the chemotherapy conditioning regimen, which leads to the post-HCT neutropenic phase and the passage of pathogenic bacteria through damaged epithelium and mucosa. Other early complications are not infection-related but equally potentially detrimental. They include engraftment rejection/failure, organ toxicity, acute graft-versus-host disease (GVHD), and other 
relatively rare complications. These latter group of complications includes sinusoidal obstruction syndrome (SOS), capillary leak syndrome, engraftment and peri-engraftment syndrome, diffuse alveolar haemorrhage, and transplant associated thrombotic microangiopathy (TA-TMA) (3-7).

Recent studies show that endothelial activation and damage are crucial not only for pathogenesis of these latter complications but is also the origin and not the consequence of acute graftversus-host disease (GVHD). Thus, they are now commonly known as early post-HCT complications of endothelial origin. In addition to early onset time, the post-HCT complications of endothelial origin share a series of common characteristics. They all start at the capillary level (systemically or in one or more organs); furthermore, they are syndromes with overlapping clinical signs and symptoms. Currently, clinical criteria for diagnosis are still not well defined and therefore diagnosing these complications is often tricky due to the lack of specific tests. Additionally, these complications can easily evolve into multiple organ failure (MOF), especially if not promptly recognized. Among early post-HCT complications of endothelial origin, GVHD is the most common and is associated with high rate of morbidity and mortality $(8,9)$.

Furthermore, endothelial cells (EC) are also involved in regulating and supporting haematopoiesis in the bone marrow micro-environment. EC dysfunction has been linked to delayed hematopoietic recovery, poor graft function and thrombocytopenia after allogeneic HCT (allo-HCT) (10). Moreover, preventing use of drugs with antioxidant and anti-inflammatory activities, like $\mathrm{N}$ acetyl-L-cysteine and atorvastatin, has been correlated with a reduction of endothelial dysfunction and a reduced incidence of poor graft function in patients $(11,12)$.

Due to their ubiquitous distribution endothelial cells (EC) are exposed to both physiologic and pathologic stimuli. For example, proinflammatory cytokines and other immunomodulatory agents transform the endothelial environment to a proinflammatory state characterized by reduced vasodilation and prothrombotic properties. This phenomenon, known as EC activation, plays main role in the inflammatory response (Figure 1). EC activation can revert back to its pre-inflammatory state or it can led to irreversible dysfunctional state (13). Endothelial dysfunction results in increased leukocytes adhesion and passage through vessel wall, platelet activation, and cytokine release. Together, they generate a vicious circle mechanism that damages the endothelial microenvironment, leading to endothelial cell apoptosis.

Carreras and colleagues demonstrated, in both autologous and allo-HCT, a significant endothelial damage and activation, even in the absence of associated complications $(14,15)$. Endothelial dysfunction can present very differently after HCT based on when and where the dysfunction occurs (see paragraphs above). The major source of endothelial damage is

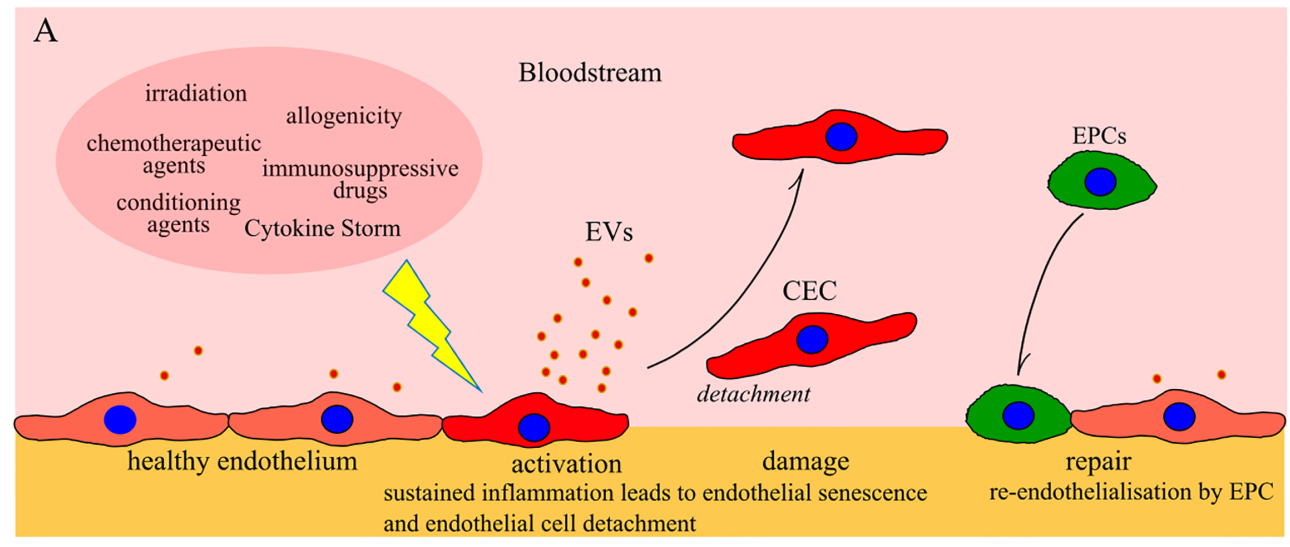

B

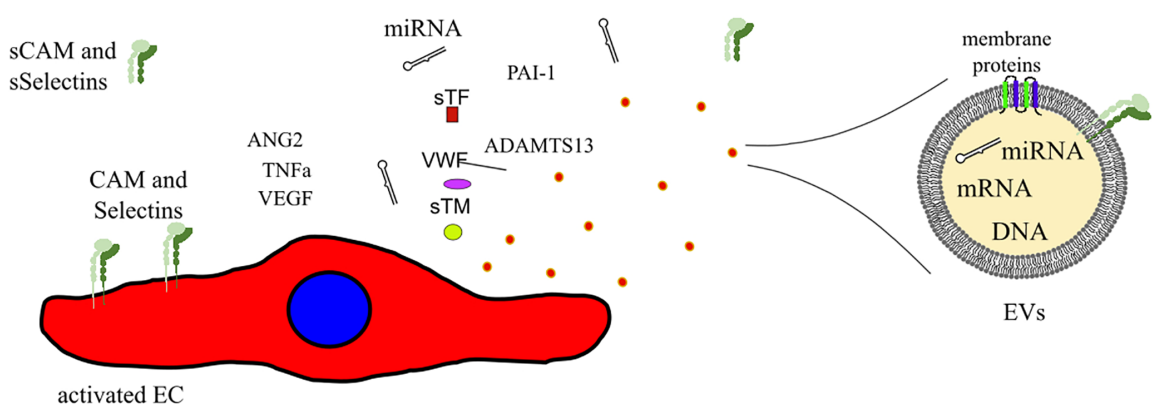

FIGURE 1 | (A) Schematic illustrating ECs activation, damage and repair after allogeneic HCT. (B) Common markers of EC damage which can potentially be used for detection of early post-HCT complications of endothelial origin. CEC: circulating endothelial cells; EPCs: progenitor endothelial cells; EVs: extracellular vesicles; CAM and SCAM: cell adhesion molecules and soluble CAM; sSelectins: soluble Selectins. 
chemo-radiotherapy used in conditioning regimens $(14,16)$. EC dysfunction is also promoted by other factors, such as cytokines release (17), bacterial lipopolysaccharides translocated through the damaged mucosal barriers (18), some drugs employed in HCT (e.g. granulocytes-colony-stimulating factor or calcineurin inhibitors) $(19,20)$, engraftment and allogeneic reactions with the donor-derived immune cells $(15,21)$.

Endothelial damage and dysregulation of new blood-vessel formation (neovascularization) are risk factors for developing these early HCT complications Therefore, identifying endothelial biomarkers for early detection of EC dysfunction could lead to early treatment and prevention of irreversible EC damage.

Most biomarker studies focus on the most common HCT complications including GVHD, TA-TMA and SOS. In this review, we describe the current biomarker research and highlight potential biomarkers that could have a potential role in clinical practise.

\section{Acute Graft Versus Host Disease}

GVHD is a complex immune reaction that occurs when activated donor $\mathrm{T}$ lymphocytes mount a destructive immune response against host tissue. Main acute GVHD organ targets are gastrointestinal (GI) tract, liver and skin. Common clinical presentations of acute GVHD include vomit and watery diarrhea, cholestasis and hyperbiliruminemia, and maculopapular rash, respectively. Between $30-50 \%$ of patients who undergo allo-HCTs develop GVHD within 100 days post-HCT (1). Some identified risk factors for GVHD are: presence of Human Leukocyte Antigens (HLA) disparity, older age and gender disparity in donors and recipients, high dose of total-body irradiation, type of GVHD prophylaxis and prior donor alloimmunization (22).

Murine models have largely contributed to this field of study and have elucidated the pathogenesis of GVHD. It is now widely accepted that GVHD develops in three sequential phases. The first phase is characterized by chemotherapy induced Antigen Presenting Cell (APC) activation. The conditioning chemo regimen triggers tissue damage and endothelial cell injury causing arteritis and loss of microvessels (23). During the first phase neutrophils, monocytes and inflammatory cells produce reactive oxygen species as a consequence of tissue damage caused by chemo/radiotherapy and eventual infections, infiltrating the GI tract. Moreover, damage- and pathogen-associated molecular pattern molecules are released from damaged tissues and activate both innate and adaptive immune responses (24). The second phase is characterized by APC activation of donor alloreactive T cells, which migrate to target tissues. In the last phase we observe an increase of Fas-ligand expression and secretion of granzyme B and perforin which mediate targeted patient cell death (25). Furthermore, a massive release of inflammatory cytokines such as interleukin (IL) 1 and 6, interferon gamma (IFN $\gamma$ ), and tumor necrosis factor alpha (TNF $\alpha$ ), plays an important role in GVHD pathophysiology and exerts cytotoxic effects on host-cell (26).

There are a number of studies using mouse models and human tissue models that confirm the theory that donor $\mathrm{T}$ cells are the driving force of alloreactivity. In vivo studies conducted by Biedermann et al. demonstrated that allogeneic reactions against ECs are associated with loss of dermal vessels and presence of CD8+ T cell infiltrates in the skin $(27,28)$. Moreover, endothelial damage in patients has been correlated with pathogenesis of steroid resistant GVHD and increased nonrelapse mortality (NMR) (29). Cordes et al. showed that sildenafil, a phosphodiesterase type 5 inhibitor known to protects EC by improving metabolic activity and reducing apoptosis decreased GVHD effects when given in combination with steroids in experimental models. Additionally, sildenafil improved animal survival reducing EC damage in liver and fibrinogen deposits in colon (30).

Studies conducted on human umbilical vein endothelial cell cultures (EC in vitro model) showed that alloreactivity and chemotherapy agents can induce endothelial apoptosis (21). In addition, EC injury and/or dysfunction can also be aggravated by the presence of lipopolysaccharide (LPS) or endotoxin (31). Moreover, preclinical mouse models and clinical observations have shown that markers of neovascularization and endothelial damage are associated with the occurrence of $\operatorname{GVHD}(32,33)$. Furthermore, the endothelium has not only a role in the pathogenesis of GVHD, but being located between the alloreactive donor T-cells and the host's tissue, is also a main exposed target for direct or indirect immune-mediated injury from either the cytotoxic T-lymphocytes or from the cytokines storm.

The complex interrelationship between endothelial damage and GVHD has led to the development of a new term called 'endothelial GVHD'; a precursor to the clinical presentation of acute GVHD (34-36). The active involvement of EC in the pathobiology of GVHD is supported in murine GVHD model where the inhibition of neovascularization has led to amelioration of GVHD symptoms and reduced mortality (32, 37). Unfortunately, at the moment very few treatments for damaged endothelium are available for routine clinical use. Interestingly, some studies shown that, in both adults and paediatric patients, the use in prophylaxis of defibrotide (DF), an approved endothelial protective drug for the treatment of SOS (38), accidentally appeared to reduce also the incidence GVHD (39-41). The reduction of GVHD promoted by DF was also confirmed by an in vivo study on mouse model (42). A phase two clinical trial (NCT03339297) is now testing whether the use in prophylaxis of DF prevents the development of GVHD.

\section{Thrombotic Microangiopathy Associated With HCT}

Transplant associated thrombotic microangiopathies (TA-TMA) are characterized by an abnormal platelet activation. This results in micro-thrombi deposition and subsequent microangiopathic hemolytic anemia. The accumulation of micro-thrombi also occludes and disrupts the microcirculation, leading to ischemic organ dysfunction, especially renal dysfunction, and neurological abnormalities. Time of onset of TA-TMA is 3 months after HCT and occurs more frequently in allo-HCT, where is typically associated to treatment with calcineurin inhibitors, compared to autologous HCT (5-15\% of patients $v s<1 \%$, respectively) (22). The collection of signs and/or symptoms associated with TATMA are highly variables and they range from asymptomatic anemia and low platelets levels to mild acute renal failure and fulminant MOF. 
The pathophysiology of TA-TMA is not completely well understood, although endothelial damage appears to have a crucial role in TA-TMA development. Additionally, damaged and dysfunctional EC have a procoagulant activity through exposure of collagen, negative charges, and Tissue Factor which lead to intravascular complement and platelets activation. Aberrant complement activation is dependent on several intrinsic and extrinsic risk factors. Intrinsic risk factors are donor specific and include female sex, age, and genetic predispositions (HLA-mismatch); extrinsic risk factors are modifiable and include conditioning regimen, viral infections, immunosuppressive therapies and GVHD (7).

Endothelial injury with aberrant complement activation can be described by a 'two-hit' process. The first "hit" makes the endothelium more procoagulant. This damage occurs in the early post-HCT aplastic phase and is generally caused by conditioning regimen in presence of concurrent risk factors (e.g. prolonged immobilization, severe infections, high dose busulfan) (43). The "second hit" causes further endothelial injury and initiates platelet aggregation and thrombus formation in microvessels. The initiating agents involved in the second "hit" phase are the use of calcineurin inhibitors, especially in association with mTOR inhibitors, the presence of GVHD and/or infections. Furthermore, some data shows that neutrophil extracellular traps (NETs) could also participate in EC damage and in complement activation. Thus, serum NETs levels are significantly elevated in the first weeks after allo-HCT in TATMA patients and could be used as a predictive biomarkers of thrombotic microangiopathy (44).

At present, there is not consensus on the diagnostic criteria for TA-TMA, other than histologic examination of the damaged tissues. Furthermore, performing a tissue biopsy for histologic diagnosis of TA-TMA is associated with potential complications in thrombocytopenic patients and cannot be considered a routine procedure. The lack of consistent non-invasive diagnostic criteria is responsible for delayed diagnosis and irreversible organ damage; therefore mortality rate in affected patients is up to $75 \%$ within 3 months from TA-TMA onset (45). Since diagnosis of TA-TMA continues to be challenging, new diagnostic criteria set has been proposed (46). A first set was proposed by the European Group for Blood and Bone Marrow Transplantation and the European Leukemia Net International Working Group. It is based on the following 5 criteria: 1) increased schistocytes; 2) new onset or worsening of thrombocytopenia 3) increased Lactate Dehydrogenase; 4) decreased haptoglobin; 5) and decreased haemoglobin concentration or increased red cell transfusion (47). The second set of criteria, proposed by the Blood and Marrow Transplant Clinical Trials Network, includes: number of schistocytes counted with optical microscopy only; Lactate Dehydrogenase; negative Coombs test; and renal dysfunction or unexplained neurological impairment (48).

\section{Sinusoidal Obstruction Syndrome}

Damage of sinusoidal and hepatic venule endothelial cell is crucial for the pathogenesis of SOS. The injury leads to platelet and fibrin deposition in the sub endothelium and fibrosis of the terminal venous venules and sinusoids. These events result in vascular occlusion and subsequent decreased hepatic venous outflow, post-sinusoidal hypertension and eventually hepatocellular necrosis and liver failure (49).

Clinically it is characterized by icterus, fluid retention, and painful enlarged liver that occurs within the first 21-40 days postHCT $(50,51)$. Cases presenting within the first 21 days are referred to as classical SOS while those presenting after day 40 are referred to as late onset SOS. Currently, SOS is diagnosed based on the following clinical criteria: hepatomegaly, ascites, elevated bilirubin level, hemodynamic or/and ultrasound evidence of SOS and it should be histologically proven (52, 53). However, these criteria are non-specific and sometimes absent at SOS onset time, causing a delay of diagnosis and treatment. Once again, tissue biopsy for histologic diagnosis might be challenging to obtain in the early post-HCT setting.

Non-invasive ultrasound imaging techniques are used in clinical practice to assist in the exclusion of differential diagnoses, and they can have a role in dubious and in late-onset cases. Nevertheless, the sensitivity and specificity of ultrasound need to be improved for early detection in transplanted patients (54).

In recent years, the incidence of SOS has declined as a result of less aggressive conditioning regimens. The majority of patients with mild-to-moderate disease may resolve SOS spontaneously, whereas the severe forms maintain a high mortality rate $(>80 \%)$ due to progression to MOF. For this reason, early detection and treatment of SOS is critical for preventing the development of severe SOS and MOF.

The risk of developing SOS is variable (3-15\%) and depends upon the type of transplant and the conditioning regimen (49). Allo-HCT recipients have a higher risk of developing SOS compared to auto-HCT recipients (5-15\% vs 3\%, respectively) $(36,51,55)$. In addition, patients who receive myeloablative conditioning experience higher rates of SOS (10-15\%) compared to those who receive a reduced intensity conditioning (51). Moreover, SOS is more frequent in patients receiving a busulfan-based conditioning regimens before $\operatorname{HCT}(38,56)$.

The other identified risk factors can be grouped into: 1) factors associated with HCT (e.g. HLA-mismatched donor, second HCT), 2) patient and disease related factors (e.g. older age, female gender, glutathione S-transferase mu 1 polymorphism or C282Y allele), and 3) hepatic related factors (e.g. pre-existing liver diseases, presence of cirrhosis, use of hepatotoxic drugs) $(49,51)$. Nevertheless, the presence of those risk factors have minimal ability to predict SOS incidence and outcomes (39).

The presence of toxic metabolites derived from conditioning chemotherapies has been proposed as the leading cause of hepatic venule and sinusoidal endothelial cell damage. Drugs breakdown occurs through the hepatic cytochrome P450 complex and produces several toxic side-products which are neutralized by the glutathione enzymatic system (GSH). In patients with a reduced GSH activity toxic side-products accumulate and can damage hepatocytes and sinusoidal endothelium. More specifically, these toxic effects predominantly affect the endothelial cells in the centrilobular 
veins because this area is poor in GSH. This toxic injury causes a cascade of events that leads to post-sinusoidal hypertension triggering SOS (49).

\section{BIOMARKERS OF ENDOTHELIAL ACTIVATION AND DAMAGE}

The endothelium is the first contact for immunological effector cells in the blood and a key regulator in various inflammatory processes. Clinical studies suggested that endothelial dysfunction plays a major role in SOS, GVHD and TA-TMA development. Since EC damage and dysfunction is a major underlying cause of early postHCT complications, several therapies targeting EC have been investigated. The most promising drugs targeting EC used for prophylaxis and treatment of early HCT complications are: defibrotide, Alpha-1 antitrypsin, statins and acetyl-L-cysteine. A reduced incidence of GVHD, SOS and TA-TMA has been observed with the preventive use of defibrotide (DF), a recognized endothelial protective drug (40), in both adults and paediatric patients $(41,57$, 58). Alpha-1 antitrypsin is a serin protease inhibitor that downmodulates inflammation in EC and it has been shown to induce a response in corticosteroid resistant GVHD patients (59). Use of statins and acetyl-L-cysteine, that target EC injury are under investigation in TA-TMA and SOS (60). Moreover, a lower incidence of SOS has been also observed on patients undergoing allo-HCT using statins (61).

The first step toward endothelial dysfunction is loss of vascular integrity and participation of EC in inflammatory response. This change in EC function and morphology could lead to a local increase in permeability, or to major endothelium contraction, resulting into subendothelial exposure (Figure 1).

Acute changes in endothelial cell protein expression occur shortly after endothelial activation/injury and alter the protein "landscape" of the cell membrane. These dynamic changes in protein expression can be harnessed as biomarkers or clinical indicators of early endothelial dysfunction. An ideal biomarker for allo-HCT complications should be characterized by a high sensitivity, specificity, and predictive value. Furthermore, it should be cost-effective and reproducible across patient populations. Unfortunately, EC damage biomarkers, which will be discussed in the next section, rarely achieve all the required criteria for the ideal biomarkers, and most of them lack specificity. Nevertheless, this translational biomarker approach could have a clinical role in the next future, as this might enable clinicians to detect alloreactivity at the micro level before it develops into an advanced clinical syndrome. Among those, soluble adhesion molecules, circulating endothelial cells and endothelial cell progenitors, coagulation factors, pro-inflammatory mediators and hyaluronic acid (HA) are all being actively tested (Table 1) $(33,62$, $66,109,110)$, and several studies are investigating their diagnostic, predictive and prognostic values in early post-HCT complications.

\section{Soluble Biomarkers}

Coagulation factors (such as Von Willebrand factor (VWF), thrombomodulin (TM), plasminogen activator type-1 (PAI-1), and VWF-cleaving protease or ADAM13 activity) and soluble cellular adhesion molecules (sCAMs) are reliable markers of EC activation and damage.

Expression of cellular adhesion molecules (CAMs) on EC surface is important for leucocytes adhesion and transmigration through blood vessel into tissues. There are two isoforms of CAMs: circulating soluble CAMs which are either secreted or cleaved, and membrane bound CAMs (111). Several studies analysed coagulation factors and soluble CAMs before and after HCT. VWF, TM and Angiogenic factors (Angiopoietin2 or ANG2), expressed by EC, were found to be increased pre-HCT, compared to healthy controls, suggesting that endothelium is already damaged and activated by the underlying hematologic disease (such as Multiple Myeloma, Lymphoma ore Leukemia) $(62,63)$.

Moreover, in the first weeks after auto- and allo-HCT an increase of VWF and soluble Intercellular CAM protein 1 (sICAM-1) has been reported $(15,62)$, while PAI-1, TM and ANG2 are only elevated in patients undergoing allo-HCT (62, 71). In addition, the serum levels of all sCAMs are known to be higher after allo- compared with auto-HCT patients (61).

These data confirm that the microenvironment of the endothelium is significantly altered in patients by the underlying hematologic disease and HCT procedure. Furthermore, additional studies have expanded on these data and discovered changes in soluble protein expression that are specific to patients with post-HCT complications such as SOS, GVHD and TA-TMA.

In another study conducted in patient undergoing allo-HCT (112), serum level of sCAMs and PAI-1 has been measured to evaluate the endothelial dysfunction level after treating patients with recombinant TM, an anticoagulant agent used for transplanted-associated coagulopathy. This study showed that there is an increase of sCAMs and PAI-1 level in all patients, confirming that endothelial damage is a common feature in alloHCT, but this increase is statistically significant only in patients not treated with recombinant TM. Moreover, patients treated with recombinant TM not only exhibited less endothelial dysfunction level, but also a significant decreased in acute GVHD frequency (112). This study represents a clear example of how endothelial biomarkers could be used to monitor therapy response in patients.

Allo-HCT patients who developed SOS, TA-TMA and GVHD had a significant increase in both VWF and TM levels $(65,69,70)$. Furthermore, levels of VWF, and TM (combined with ICAM-1 and E-selectin level) measured one week after HCT were used as SOS predicting biomarker in patients treated with both tacrolimus and sirolimus as GVHD prophylaxis (65).

Circulating levels of PAI-1 were elevated in patients with SOS, but not in those with GVHD $(15,69)$. Increased PAI-1 levels not only allow differential diagnosis between SOS and GVHD, but also from other liver injuries $(72,73)$. Conversely, decreased PAI-1 levels within the first two weeks of DF administration has been correlated with complete SOS response at three months post-HCT (57). Nevertheless, PAI-1 marker performed poorly in proteomic-based approach and it was not included as predictive marker in the final composite biomarker panel (66). 
TABLE 1 | Main biomarkers (references) described for endothelium damage, and for GVHD, SOS, and TA-TMA prediction, diagnosis, or risk stratification.

\begin{tabular}{|c|c|c|c|c|c|c|c|c|c|c|c|}
\hline Biomakers & $\begin{array}{c}\text { Sample } \\
\text { requirements }\end{array}$ & $\begin{array}{l}\text { Detection } \\
\text { methods }\end{array}$ & $\begin{array}{l}\text { After } \\
\text { HCT }\end{array}$ & Level & GVHD & $\begin{array}{l}\text { Level and } \\
\text { clinical value }\end{array}$ & Clinical trial & sos & $\begin{array}{l}\text { Level and } \\
\text { clinical value }\end{array}$ & $\begin{array}{l}\text { TA- } \\
\text { TMA }\end{array}$ & $\begin{array}{c}\text { Level and } \\
\text { clinical value }\end{array}$ \\
\hline SICAM-1 & Senun/plasma & ELISA & $\begin{array}{c}(15 \\
62-64)\end{array}$ & increased & $(64,65)$ & $\begin{array}{l}\text { Increased PG } \\
\text { PG }\end{array}$ & & $\begin{array}{l}(64- \\
67)\end{array}$ & Increased PG Pr & & \\
\hline sVCAM-1 & Serum/plasma & ELISA & $\begin{array}{l}(62- \\
64)\end{array}$ & increased & (64) & Increased PG & & $(67)$ & Increased PG D & (64) & Increased PG \\
\hline sE-selectin & Serum/plasma & ELISA & $\begin{array}{c}(62 \\
64,68)\end{array}$ & increased & (65) & Increased PG & & (65) & Increased PG Pr & (64) & Increased PG \\
\hline sP-selectin & Serum/plasma & ELISA & $\begin{array}{c}(62 \\
64,68)\end{array}$ & increased & & & & $\begin{array}{l}(64, \\
68)\end{array}$ & Increased PG Pr & & \\
\hline WWF & Serum/plasma & ELISA & $\begin{array}{l}(62, \\
69)\end{array}$ & increased & $(65,69)$ & Increased & & $\begin{array}{l}(65, \\
69)\end{array}$ & Increased PG & (70) & increased \\
\hline TM & Serum/plasma & ELISA & $\begin{array}{l}(62 \\
71)\end{array}$ & increased & $(65,69)$ & Increased & & $\begin{array}{l}65 \\
69\end{array}$ & Increased PG & $\begin{array}{l}(64, \\
70)\end{array}$ & increased \\
\hline PAI-I & Serum/plasma & ELISA & $\begin{array}{l}(62 \\
71)\end{array}$ & increased & & & & $\begin{array}{l}(15 \\
69 \\
72 \\
73)\end{array}$ & Increased D PG & (49) & increased \\
\hline ADAM13 & Serum/plasma & ELISA & (15) & increased & & & & & & & \\
\hline VEGF & Serum/plasma & ELISA & $(74)$ & increased & (75) & Increased PG & & (74) & increased & & \\
\hline ANG2 & Serum/plasma & ELISA & $\begin{array}{c}(62 \\
63,71)\end{array}$ & increased & (63) & Increased PG & & $(66)$ & Increased D PG & & \\
\hline CEC & $\mathrm{PB}$ & Flow-cytometry & $\begin{array}{l}(76, \\
77)\end{array}$ & increased & $(78,79)$ & $\begin{array}{l}\text { Increased D } \\
\text { PG }\end{array}$ & & & & & \\
\hline EPC & $\mathrm{PB}$ & Flow-cytometry & $\begin{array}{l}(80, \\
81)\end{array}$ & decreased & & & & & & & \\
\hline EV & Serum/plasma & Flow-cytometry & (82) & Increased & $(83-85)$ & $\begin{array}{l}\text { Antigen- } \\
\text { depend. Pg Pr }\end{array}$ & & $\begin{array}{l}(66 \\
86)\end{array}$ & $\begin{array}{l}\text { Antigen-depend. D } \\
\text { PG }\end{array}$ & & \\
\hline miRNAs & Serum/plasma & $\begin{array}{l}\text { RT-PCR, micro- } \\
\text { seq. micro-array }\end{array}$ & & & $\begin{array}{l}(85 \\
87-92)\end{array}$ & $\begin{array}{l}\text { miRNA- } \\
\text { depend. PG } \\
\text { Pr }\end{array}$ & & (82) & $\begin{array}{l}\text { Mouse model } \\
\text { miRNA-depend. } \\
\text { PG }\end{array}$ & & \\
\hline TNFRI & Serum/plasma & ELISA & & & $(93,94)$ & $\begin{array}{l}\text { Increased PG } \\
\text { Pr }\end{array}$ & NCT0280694 & & & & \\
\hline TNFa & Serum/plasma & ELISA & & & (95) & $\begin{array}{l}\text { Increased PG } \\
\text { Pr }\end{array}$ & & (95) & Increased PG & & \\
\hline ST2 & Serum/plasma & ELISA & & & $\begin{array}{l}(93 \\
96-101)\end{array}$ & $\begin{array}{l}\text { Increased D } \\
\text { PG Pr }\end{array}$ & NCT0280694 & (66) & Increased D & & \\
\hline REG3a & Serum/plasma & ELISA & & & $\begin{array}{l}(93 \\
98-100)\end{array}$ & $\begin{array}{l}\text { Increased D } \\
\text { PG }\end{array}$ & NCT0022487 & (67) & Increased PG & & \\
\hline TIM3 & Serum/plasma & ELISA & & & $\begin{array}{r}(94 \\
101)\end{array}$ & $\begin{array}{l}\text { Increased D } \\
\text { PG }\end{array}$ & & $(67)$ & Increased PG & & \\
\hline $\mathrm{HA}$ & Serum/plasma & ELISA & & & & & & (66) & Increased D PG & & \\
\hline L-Ficolin & Serum/plasma & ELISA & & & & $\begin{array}{l}\text { Increased PG } \\
\text { Pr }\end{array}$ & & (66) & Increased D & & \\
\hline IL6 & Serum/plasma & ELISA & & & $\begin{array}{l}(94 \\
102 \\
103)\end{array}$ & $\begin{array}{l}\text { Increased D } \\
\text { PG }\end{array}$ & & $\begin{array}{l}(102 \\
103)\end{array}$ & & & \\
\hline slL2Ra & Serum/plasma & ELISA & & & $(68,98)$ & $\begin{array}{l}\text { Increased D } \\
\text { PG }\end{array}$ & NCT0022487 & (95) & Increased PG & & \\
\hline Haptoglobin & Serum/plasma & ELISA & & & & & & & & $(104)$ & Increased PG \\
\hline NETs & Serum/plasma & ELISA & $(40)$ & increased & & & & & & $(40)$ & Increased PG \\
\hline EASIX & panel & panel & $\begin{array}{l}(105 \\
106)\end{array}$ & $\begin{array}{l}\text { Increased } \\
\text { Pr }\end{array}$ & $\begin{array}{r}(86, \\
107)\end{array}$ & $\begin{array}{l}\text { Increased PG } \\
\text { Pr }\end{array}$ & & (61) & Increased D & (105) & Increased PG \\
\hline MAGIC & panel & panel & & & $\begin{array}{l}(98- \\
100 \\
108)\end{array}$ & $\begin{array}{l}\text { Increased PG } \\
\text { Pr }\end{array}$ & & & & & \\
\hline
\end{tabular}

HCT, stem cell transplant; GVHD, acute graft-versus-host disease; SOS, sinusoidal obstruction syndrome; TA-TMA, transfusion associated thrombotic microangiopathy; miRNAs,

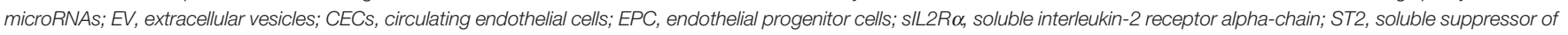

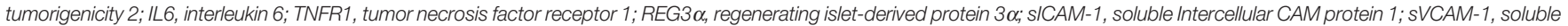
vascular CAM protein 1; WWF, Von Willebrand factor; TM, thrombomodulin; HA, hyaluronic acid; PAl-1, plasminogen activator type-1; VEGF, vascular endothelial growth factor; ANG2, Angiopoietin2; NETs, neutrophil extracellular traps; EASIX, Endothelial Activation and stress index panel; MAGIC, Mount Sinai Acute GVHD International Consortium panel; TIM3, T-cell immunoglobulin and mucin domain-containing protein 3; TNFa, tumor necrosis factor alpha; PB, peripheral blood; D, diagnostic; Pr, predictive; PG, prognostic; PB, peripheral blood; ELISA, Enzyme-linked immunosorbent assay; micro-seq, miRNAs sequencing. 
Thus, concentration of soluble ICAM-1 and E-selectin is elevated in both GVHD and SOS patients (65); soluble vascular CAM protein 1 (sVCAM-1) increased especially in patients who later develop GVHD and TA-TMA, while Pselectin levels was selectively higher in patients developing severe SOS $(64,68)$.

Recently, Akil et al. showed that a composite diagnostic biomarker panel (L-Ficolin, hyaluronic acid (HA), VCAM-1) can identify patients at high risk of SOS as early as the first day after HCT, even before clinical manifestation of SOS (66). In addition, the use of the following biomarker panel: suppression of tumorigenicity-2 (ST2), ANG2, L-Ficolin, HA, VCAM-1 was suggested to be useful for SOS diagnosis (66).

Circulating angiogenic factors level (e.g. vascular endothelial growth factor (VEGF) and ANG2) is varied among patients with GVHD and SOS. In some studies, HCT patients had lower VEGF serum concentration compared to healthy volunteers. In contrast, in the same setting, VEGF tends to increase in patients with GVHD and SOS $(74,75)$. The high level of VEGF might be diagnostic of GVHD, but not predictive as levels of VEGF were not increased prior to GVHD onset (75). In contrast, ANG2 expression is elevated prior to $\mathrm{HCT}$, and there is an additional observed increase in ANG2 levels associated after the development of GVHD (63).

Inflammatory cytokines such as IL2, IL6, IL33, IFN $\gamma$, and TNF $\alpha$ are crucial for EC activation and damage (102, 103). $\mathrm{TNF} \alpha$ is an inflammatory cytokine involved in damage initiation and spreading in acute GVHD (113). However, TNF $\alpha$ raised also in other post-HCT complications, such as SOS $(114,115)$. IL2 is a cytokine with critical effects on T-cell physiology. Many studies reported increased soluble IL2 receptor $\alpha(\operatorname{sIL} 2 \mathrm{R} \alpha)$ concentration prior to clinical onset of GVHD and its predictive role in both GVHD development and severity (116118). Similarly to TNF $\alpha$, sIL $2 \mathrm{R} \alpha$ also rise in other HCT complications, such as SOS and bacterial infections and cannot be considered as a specific biomarker for GVHD (95).

IL33 is a cytokine belonging to IL1 family that binds ST2. Dysregulation of ST2/IL33 signaling pathway was originally described in the context of different inflammatory diseases $(119,120)$. Additionally, IL33 upregulates the expression of CAMs in human EC (120) and an altered secretion of soluble ST2 by intestinal cells has been observed in experimental models of GVHD (121). Soluble ST2 has been validated as a biomarker for treatment-resistant GVHD, and elevated circulating ST2 at day +7 or +14 post-HCT can also be predictive of NRM following $\operatorname{HCT}(96,97)$.

Discovered as GVHD biomarker by proteomic analysis, ST2 has been correlated with other promising GVHD biomarkers, such as the antimicrobial peptide regenerating islet-derived protein 3 alpha $(\mathrm{REG} 3 \alpha)$, and soluble tumor necrosis factor receptor 1 (TNFR1). These biomarkers have been tested in large multicentre consortia, and identified patients developing GVHD one week after HCT or at disease onset $(93,97,98)$.

IL-2R $\alpha$, combined with measurement of regenerating isletderived protein 3 alpha or REG3 $\alpha$ [a GVHD target organspecific damage biomarkers (122)] and ST2 enabled the development of a validated predictive algorithm (Mount Sinai Acute GVHD International Consortium or MAGIC), based on ST2 and REG3 $\alpha$ concentrations after one week of systemic glucocorticoid treatment, to predict life-threatening GVHD and NRM (98). Recent studies suggest that the measurement of REG3 $\alpha$ and ST2 in haplo HCT may be associated with a higher incidence of GVHD and NRM (99, 100). Moreover, MAGIC predictive algorithm not only is prognostic for NMR and overall survival, but it can be used as response biomarker for acute GVHD treatment (108).

Other biomarker combinations, such as ST2+REG3 $\alpha+$ TNFR1 (96), ST2+TNFR1, T cell immunoglobulin and mucin domaincontaining protein 3 (TIM3) +TNFR1+IL6 (94), ST2+TIM3 (101), have been investigated in the plasma of HSC patients and improve detection and severity of GVHD. Furthermore, plasma levels of REG3 $\alpha$, sVCAM1, sICAM1, and TIM3 at two weeks post- HCT were consistently elevated in patients who developed SOS (67).

Moreover, a new biomarker panel called EASIX (or Endothelial Activation and stress index) appeared to predict overall survival, NMR, and risk of poor outcomes in patient undergoing to allo-HCT $(105,106)$. EASIX score combines three routine laboratory tests that are used as diagnostic parameters of TA-TMA and is calculated using the following formula: (Lactate Dehydrogenase (U/L)) x (Creatinine (mg/ $\mathrm{dL})$ )/Thrombocytes $\left(10^{9}\right.$ cells per L). Elevated EASIX score at days 0 after HCT has been showed to predict the risk of mortality in patients with acute GVHD and TA-TMA (86, 107). This easy-to-calculate index can be used by clinicians as a tool for clinical management of decision in patient with GVHD in the reduced conditioning regimen setting, since this index was not predictive in case of myeloablative conditioning regimens (86). Furthermore, this index has been tested in a retrospective cohort study analysis to be an independent predictor of risk of developing SOS (61). EASIX have been also used to monitor EC protective efficacy of ursodeoxycholic acid and statins in transplanted patients. Post-HCT prophylactic use of these two drugs was associated with lower EASIX score, which indicate less endothelial damage, lower SOS incidence, and better clinical outcomes (low NMR and high overall survival) (61).

Recently, proteomics profiling on serum from patients undergoing HCT allows the discovery of a $17 \mathrm{KDa}$ haptoglobin degradation product that was differentially expressed in patients who developed TA-TMA. This non-invasive biomarker showed diagnostic value toward TA-TMA and could potentially allow earlier intervention (104). Furthermore, haptoglobin has been proposed to be used in TA-TMA diagnostic criteria (47).

\section{Circulating Endothelial Cells and Endothelial Progenitor Cells}

There are two categories of circulating cells that have been proposed as biomarker of endothelial damage; they include circulating endothelial cells (CEC) and endothelial progenitor cells (EPC). The presence of CEC and EPC in blood and their level measure vascular health homeostasis, being CEC a 
recognized biomarkers of ongoing endothelial damage, whereas EPC evaluate vascular repair suitability $(80,123)$.

Prolonged or unregulated endothelial damage often results in a loss of EC integrity and shedding of mature endothelial cells into the bloodstream (124). CEC are a rare cellular subpopulation in peripheral blood and are usually absent in the blood of healthy individuals. They are characterized by the expression of endothelial markers (VWF, CD31, CD144, and CD146) and the absence of leucocyte markers. Currently, the most used biomarkers for CEC detection is CD146, which can be used to increase specificity in combination with other biomarkers, such as VEGFR2 and CD133 (125). Analysis of CEC count in HCT showed that there is an earlier CEC peak in patients receiving total body radiation compared to patients receiving chemotherapy (76). Furthermore, CEC count is lower in patients receiving reduced-intensity conditioning regimen compared to those receiving myeloablative conditioning regimen (77).

By contrast, EPC are bone marrow-derived cells found in peripheral blood that contribute to angiogenesis and to vascular repair after endothelium damage. EPC are characterized by the expression of CD34, CD133, VEGFR2, VWF, CD117, and CD144; a combination of these markers have been used to identify EPC by flow cytometry (123). Although EPC are present in the bloodstream of healthy individuals, patients undergoing allo HCT have lower EPC counts than healthy volunteers, even before transplantation. Even though the EPC count seemed to recover partially twelve month post-HCT, EPC remain lower compared to healthy controls (81).

CEC are considered more sensitive compared to EPC in detecting EC damage. As CEC could even be used as a diagnostic biomarker of EC damage in the early phases of a disease, many studies have been trying to improve the sensitivity of CEC detection and their diagnostic sensitivity (123).

Almici et al. described a relative CEC count increase in patients developing GVHD compared to those without GVHD, and was associated with engraftment as well (78). Moreover, the CEC level can be treated also as marker of GVHD therapy response, as levels tend to return to basal pre-transplant value in responding patients. CEC count is now considered a dynamic phenomenon because is affected by several factors, such as the conditioning regimen, engraftment, infections and immunosuppressive treatments. Nevertheless, cytofluorimetric enumeration of CEC is still not a standardized procedure since different CEC tagging approaches bring complimentary, but not completely overlapping, results (CEC identified as CD146+CD106+CD45-cells or as CD34+CD45-CD146+cells, by CellSearch system or polychromatic flow-cytometry, respectively) (79).

\section{MiRNAs and Extracellular Vesicles}

Two new categories of biomarkers undergoing active investigation are microRNAs (miRNAs) and extracellular vesicles (EVs).

MiRNAs represent a family of non-coding RNAs of 19-25 nucleotides, that regulate gene expression increasing the degradation or blocking translation of a target messenger RNA (126). MiRNAs are presents in all biological fluids and are released by cells mainly in three different forms: as freely circulating miRNAs, as protein-associated (like argonaute 2 and nucleophosmin 1) or encapsulated in EVs. Freely diffusing miRNAs are mainly released by damaged or death cells, whereas miRNAs encapsulated in EVs are specifically released by cells as messengers. Moreover, miRNAs transported by EVs are protected from RNAse degradation, and thus are more stables and specific than freely circulating miRNAs. Several studies suggested the potential use of miRNAs as biomarker in many human diseases including their role as potential biomarker in in early post-HCT complications like GVHD.

Many free circulating miRNAs are differentially expressed in plasma/serum a diagnosis (pre-transplant), two weeks after HCT and before onset of GVHD, such as: miR155, miR146a, miR19a, miR20a, miR30, miR181, miR150, miR194, miR100 and miR518f (87-91) showing a possible prognostic use in GVHD. Moreover, differential expression of some miRNAs, such as miR19b, miR20a and miR30b, has been linked to improved overall survival (91), indicating a possible predictive role in clinical routine.

Mir155 is a strong example of a miRNA which can potentially be used not only as a biomarker but also as therapeutic target. Serum up-regulation of miR155 has been observed in patients with confirmed GI-GVHD (90) and in effector T cells from a murine GVHD experimental model (127). Furthermore, mice receiving miR155-deficient donor lymphocytes had a lower GVHD incidence and improved survival rate, whereas lethal GVHD developed rapidly in mice with T-cell miR155overexpressions. Consistently, blocking miR155 function with a synthetic oligonucleotide complementary to miR155 improved GVHD symptoms (127).

Clinical studies investigating the role of miRNA as SOS and TA-TMA biomarkers in patients are missing. In a rodent model, where SOS is induced by monocrotaline, serum miRNA profile reveals that miR21-5p and miR511-3p could be used as early predictive biomarkers for SOS (82). Those miRNAs were increased in serum during the early phase of SOS, probably in response to liver sinusoidal EC damage, while the miR122-5p, miR192-5p, and miR101b-3p could be used as indicators for hepatocyte damage in later phase (82). Future clinical studies are necessary to elucidate whether these miRNAs could also be used as biomarkers in TA-TMA and SOS clinical prediction and diagnosis in patients; nevertheless, those preliminary results are encouraging.

Extracellular vesicles (EVs) are cell-derived particles delimited by a membrane, which are important for intercellular communication by shuttling bio-acting molecules (miRNAs, messenger RNA, DNA, proteins, lipids and carbohydrates) through biological barriers from one cell to another (128).

EVs are an highly heterogeneous group of particles including microvesicles and exosomes, which differ for dimensions and cellular origin (128). Owing to their cargo content (miRNAs, proteins, and other bioactive molecules) and capacity to deliver 
their cargo to specific cells, EVs are involved in homeostasis maintenance and regulation of physiological functions, but also in different pathological processes (e.g. in cancer, inflammation and autoimmune diseases) (129). EVs cargo composition can differ among EVs subpopulations depending on the originating cell type, therefore this vast heterogeneity could be responsible for different biological effects mediated by EVs subgroups (130-132).

The discovery that EVs concentration and cargo composition is altered in patients compared to healthy people suggested their potential diagnostic value. Thus, several studies have been focused on quantification and characterization of serum/ plasma EVs membrane proteins (by flow cytometry), and EVs miRNAs content (by molecular techniques).

Endothelial cells constitutively release extracellular vesicles in a low concentration in the blood stream in physiologic conditions. However, endothelial-EVs (EEVs) release increases after EC activation and injury $(133,134)$. Typically, EEVs express endothelial markers such as CD146, CD105, CD144, CD54, CD62E, CD31, and VWF $(135,136)$. Furthermore, proinflammatory cytokines, circulating angiogenic factors, CRP and PAI-1 trigger the release of EEVs $(92,137,138)$. TNF $\alpha$ $(92,139)$ is a strong activator of ECs and leads to a dosedependent release of EEVs (137). EVs released after proinflammatory cytokine stimulation are enriched with endothelial markers and specific miRNAs (e.g. miR328-3p, let7d-3p, miR59, miR191, miR423) which are generally absent or expressed in lower concentration in physiologic conditions (92). Moreover, the concentration change of EEVs could be used as marker of endothelial dysfunction. As matter of fact, the number of EVs expressing CD31+/annexin V+ or CD42- CD31+ positively correlates with impaired endothelial function and major adverse cardio-vascular events $(83,140,141)$, while the decrease of $\mathrm{CD} 62+\mathrm{EVs}$ has been proposed as biomarker of severe endothelium damage $(80,142)$. Concentration change over time of EVs wearing these biomarkers combination could be used to monitor EC damage/dysfunction as other "classical" EC biomarkers.

Therefore, besides the concentration change of EEVs, the content and type of EVs released vary during EC activation (143, 144). Thus, temporal analysis of EEVs membrane protein immune-profile and molecular characteristic could provide clinically useful and actionable information on endothelial status and could predict early post-HCT complications.

Recent studies investigated EVs as biomarkers in SOS and GVHD $(66,86)$. Piccin et al. observed an early post-HCT increase of CD144+ EVs in plasma specimens of SOS patients, which supports the presence of early EC damage (145). Furthermore, the concentration of PAI-1 showed an interesting inverse correlation with EEVs (CD144+) and with EV CD31+/ CD41+ levels. This high level of CD144+ EVs observed in the first week post-HCT could have a diagnostic and prognostic role in SOS.

Lia et al. investigated the potential role of serum EEVs as biomarkers of GVHD (84). In this study, they observed a statistically significant expression change post-HCT of three
EVs membrane antigens prior to the onset of GVHD, notably an expression increase with CD146, while an expression decrease with CD31 and CD140a. This result showed that monitoring the expression level change compared to basal pre-HCT level of those EVs biomarker could have a prognostic GVHD application in clinical routine. A similar study published by Lia et al. confirmed the correlation between GVHD onset with CD146, CD31 and CD140a plasma EVs expression (85). Furthermore, Zhang et al. has demonstrated that EEVs originated after in vitro TNF $\alpha$ stimulation of human umbilical vein endothelial cells are enriched in miR155 (146). Moreover, levels of EVs encapsulated miR155 was significantly higher than free circulating miR155 in both GVHD patients and animal models. The role of miR155 in pathogenesis of GVHD was also confirmed by another study which observed a change in expression of miR155 in serum EEVs before GVHD onset, together with miR100 and miR194 (85). These two studies suggested a possible prognostic use of these miRNAs. Furthermore, inhibition of miR155 by loading a small complementary synthetic RNA molecule inside EEVs reduce differentiation toward proinflammatory T-cell subsets promoting anti-inflammatory response, which ameliorated GVHD effects.

However, despite their promising potential application in the clinical field, EVs and miRNAs use as biomarkers is still in its early stages, mainly due to the lack of standardized protocols in specimen handling, isolation, and analysis methods. Nevertheless, miRNAs and EVs meet the accessibility, high specificity, and sensibility criteria for being an ideal biomarker and the improvement of sampling and isolation techniques, as well as the quantification methods may result in their use as reliable tool in the future.

\section{CONCLUSIONS AND PERSPECTIVES}

The use of non-invasive biomarkers for detection and diagnosis of early post-HCT endothelial complications is a promising field of research with lifesaving implications. There are a number of potential biomarkers that have yet to be validated in clinical trials and a number of studies have also produced conflicting results. The lack of consistency among studies are probably due to differences in technique and treatment, as well as heterogeneity of patients. Reconciling these studies is also difficult due to the differences in timing, intensity of conditioning therapy, source of hematopoietic cells, and applied statistical methods. Thus, predictive biomarkers research might need a multicenter approach with coordinated times of sampling and centralized analysis of biomarker levels and standardized protocols. Moreover, the reduction of confounding variables among studies can be achieved through rigorous selection, acquisition, and storage of biological specimens.

Many of the current existing EC damage/dysfunction biomarkers lack specificity (such as CAMs, inflammatory cytokines, miRNAs, EVs) as change in their levels could be caused by different post-HCT underlying conditions. Nevertheless, they could have some clinical applications either 
in monitoring response in patients, or in detecting EC damage before its clinical development.

However, differently from other clinical routine tests, these biomarkers need to be tested at multiple time points and the comparison of pretransplant levels with later ones is essential to predict outcome.

At the moment, among the proposed GVHD biomarker panels, MAGIC is the closest to clinical application, as it has been validated and some clinical centers have recently started to use it. By contrast, available data on biomarkers for SOS and TATMA close to clinical use are still missing, and more studies are needed to identify more reliable and useful markers. Nevertheless, recently EASIX panel showed its value in stratifying patients at high risk for SOS, and in predicting OS and NRM in reduced intensity conditioning regimen allo-HCT. It is predictable that this panel, which is composed by validated routine clinical tests, will come into use in allo-HCT setting in the next future.

The Proteomics approaches has promoted the discovery or more sensitive and specific biomarker, which composed the validated MAGIC panel.

In the next future, advances in the field of Omics methodologies will expand the library of new biomarkers following a biology-driven development approach. Biology driven approaches for identification of combinatorial biomarker panel are generally divided in three distinct phases characterized by different technology approaches: Biomarker Discovery, Validation and Qualification. The Omicapproaches (e.g. mass spectrometry based proteomic approaches, array based transcriptomes approaches), generating large amount of data, are suitable for biomarker discovery and the number of potential generated biomarker

\section{REFERENCES}

1. D'Souza A, Fretham C. Current Uses and Outcomes of Hematopoietic Cell Transplantation (HCT): CIBMTR Summary Slides (2018). Available at: www.cibmtr.org.

2. Singh AK, McGuirk JP. Allogeneic Stem Cell Transplantation: A Historical and Scientific Overview. Cancer Res (2016) 76:6445-51. doi: 10.1158/00085472.CAN-16-1311

3. Crossland RE, Norden J, Kralj Juric M, Pearce KF, Lendrem C, Bibby LA, et al. Serum and Extracellular Vesicle MicroRNAs miR-423, miR-199, and Mir-93* As Biomarkers for Acute Graft-Versus-Host Disease. Front Immunol (2017) 8:1446. doi: 10.3389/fimmu.2017.01446

4. Xie Z, Ghosh CC, Patel R, Iwaki S, Gaskins D, Nelson C, et al. Vascular Endothelial Hyperpermeability Induces the Clinical Symptoms of Clarkson Disease (the Systemic Capillary Leak Syndrome). Blood (2012) 119:4321-32. doi: 10.1182/blood-2011-08-375816

5. Lee Y-H, Rah W-J. Pre-Engraftment Syndrome: Clinical Significance and Pathophysiology. Blood Res (2016) 51:152. doi: 10.5045/br.2016.51.3.152

6. Jeong G, Lee K, Lee I, Oh J, Kim D, Shin J, et al. Incidence of Capillary Leak Syndrome as an Adverse Effect of Drugs in Cancer Patients: A Systematic Review and Meta-Analysis. J Clin Med (2019) 8:143. doi: 10.3390/ jcm8020143

7. Khosla J, Yeh AC, Spitzer TR, Dey BR. Hematopoietic Stem Cell TransplantAssociated Thrombotic Microangiopathy: Current Paradigm and Novel Therapies. Bone Marrow Transplant (2018) 53:129-37. doi: 10.1038/ bmt.2017.207 candidates need to be refined using bioinformatics tool. The discovered biomarkers (usually up to 10-100 candidates) need then to be validated in other independent cohort using different reliable techniques (like ELISA). Data obtained are then analysed using data mining methods that are based on biological information's such as tissue expression patterns, clinical relevance, pathways analysis tool, etc. The validated biomarkers (generally <10) need to be tested in the qualification phase on clinical trial.

Biology driven approaches in biomarker development have the disadvantages to be time consuming, but these approaches could potentially find more sensitive and specific biomarkers.

No single biomarker presented in this review is sufficiently sensitive or specific by itself as either a diagnostic or predictive/ prognostic test. Due to the involvement of many factors promoting EC damage and pathogenesis of these complications, a panel of biomarkers has more chance to turn into a prognostic or diagnostic tool in the next future.

\section{AUTHOR CONTRIBUTIONS}

GL, LG, SL and BB devised and wrote the manuscript. All authors contributed to the article and approved the submitted version.

\section{FUNDING}

This work was supported by Italian Ministry of Education, University and Research (MIUR Bando Ricerca Locale 2018 and 2019).

8. Gratwohl A, Pasquini MC, Aljurf M, Atsuta Y, Baldomero H, Foeken L, et al. One Million Haemopoietic Stem-Cell Transplants: A Retrospective Observational Study. Lancet Haematol (2015) 2:e91-e100. doi: 10.1016/ S2352-3026(15)00028-9

9. Pidala J, Kurland B, Chai X, Majhail N, Weisdorf DJ, Pavletic S, et al. Patient-Reported Quality of Life is Associated With Severity of Chronic Graft-Versus-Host Disease as Measured by NIH Criteria: Report on Baseline Data From the Chronic Gvhd Consortium. Blood (2011) 117:4651-7. doi: 10.1182/blood-2010-11-319509

10. Yan Z, Zeng L, Li Z, Zhang H, Chen W, Jia L, et al. Bone Marrow-Derived Endothelial Progenitor Cells Promote Hematopoietic Reconstitution After Hematopoietic Stem Cell Transplantation. Transplant Proc (2013) 45:42733. doi: 10.1016/j.transproceed.2012.03.064

11. Shi M-M, Kong Y, Song Y, Sun Y-Q, Wang Y, Zhang X-H, et al. Atorvastatin Enhances Endothelial Cell Function in Posttransplant Poor Graft Function. Blood (2016) 128:2988-99. doi: 10.1182/blood2016-03-702803

12. Kong Y, Wang Y, Zhang Y-Y, Shi M-M, Mo X-D, Sun Y-Q, et al. Prophylactic Oral NAC Reduced Poor Hematopoietic Reconstitution by Improving Endothelial Cells After Haploidentical Transplantation. Blood Adv (2019) 3:1303-17. doi: 10.1182/bloodadvances.2018029454

13. Aird WC. Phenotypic Heterogeneity of the Endothelium. Circ Res (2007) 100:158-73. doi: 10.1161/01.RES.0000255691.76142.4a

14. Palomo M, Diaz-Ricart M, Rovira M, Escolar G, Carreras E. Defibrotide Prevents the Activation of Macrovascular and Microvascular Endothelia Caused by Soluble Factors Released to Blood by Autologous Hematopoietic 
Stem Cell Transplantation. Biol Blood Marrow Transplant (2011) 17:497506. doi: 10.1016/j.bbmt.2010.11.019

15. Palomo M, Diaz-Ricart M, Carbo C, Rovira M, Fernandez-Aviles F, Martine C, et al. Endothelial Dysfunction After Hematopoietic Stem Cell Transplantation: Role of the Conditioning Regimen and the Type of Transplantation. Biol Blood Marrow Transplant (2010) 16:985-93. doi: $10.1016 /$ j.bbmt.2010.02.008

16. Estey EH. Intensity of Conditioning for Allogeneic Haemopoetic Cell Transplantation. Lancet Oncol (2012) 13:966-8. doi: 10.1016/S1470-2045 (12)70374-1

17. Zhang C. The Role of Inflammatory Cytokines in Endothelial Dysfunction. Basic Res Cardiol (2008) 103:398-406. doi: 10.1007/s00395-008-0733-0

18. Eissner G, Multhoff G, Holler E. Influence of Bacterial Endotoxin on the Allogenicity of Human Endothelial Cells. Bone Marrow Transplant (1998) 21:1286-8. doi: 10.1038/sj.bmt.1701264

19. Fusté B, Mazzara R, Escolar G, Merino A, Ordinas A, Díaz-Ricart M. Granulocyte Colony-Stimulating Factor Increases Expression of Adhesion Receptors on Endothelial Cells Through Activation of p38 Mapk. Haematologica (2004) 89:578-85.

20. Mercanoglu F, Turkmen A, Kocaman O, Pinarbasi B, Dursun M, Selcukbiricik F, et al. Endothelial Dysfunction in Renal Transplant Patients is Closely Related to Serum Cyclosporine Levels. Transplant Proc (2004) 36:1357-60. doi: 10.1016/j.transproceed.2004.05.073

21. Palomo M, Diaz-Ricart M, Carbo C, Rovira M, Fernandez-Aviles F, Escolar G, et al. The Release of Soluble Factors Contributing to Endothelial Activation and Damage After Hematopoietic Stem Cell Transplantation Is Not Limited to the Allogeneic Setting and Involves Several Pathogenic Mechanisms. Biol Blood Marrow Transplant (2009) 15:537-46. doi: 10.1016/j.bbmt.2009.01.013

22. E Carreras, C Dufour, M Mohty and N Kröger eds. The EBMT Handbook. Cham: Springer International Publishing (2019). doi: 10.1007/978-3-03002278-5

23. Riesner K, Shi Y, Jacobi A, Kräter M, Kalupa M, McGearey A, et al. Initiation of Acute Graft-Versus-Host Disease by Angiogenesis. Blood (2017) 129:2021-32. doi: 10.1182/blood-2016-08-736314

24. Zeiser R, Blazar BR. Acute Graft-versus-Host Disease - Biologic Process, Prevention, and Therapy. N Engl J Med (2017) 377:2167-79. doi: 10.1056/ NEJMra1609337

25. Baker MB, Altman NH, Podack ER, Levy RB. The Role of Cell-Mediated Cytotoxicity in Acute GVHD After MHC-matched Allogeneic Bone Marrow Transplantation in Mice. J Exp Med (1996) 183:2645-56. doi: 10.1084/ jem.183.6.2645

26. Zeiser R. Advances in Understanding the Pathogenesis of Graft-Versus-Host Disease. Br J Haematol (2019) 187:563-72. doi: 10.1111/bjh.16190

27. Biedermann BC, Sahner S, Gregor M, Tsakiris DA, Jeanneret C, Pober JS, et al. Endothelial Injury Mediated by Cytotoxic T Lymphocytes and Loss of Microvessels in Chronic Graft Versus Host Disease. Lancet (2002) 359:207883. doi: 10.1016/S0140-6736(02)08907-9

28. Biedermann BC. Vascular Endothelium and Graft-Versus-Host Disease. Best Pract Res Clin Haematol (2008) 21:129-38. doi: 10.1016/ j.beha.2008.02.003

29. Andrulis M, Dietrich S, Longerich T, Koschny R, Burian M, Schmitt-Graf A, et al. Loss of Endothelial Thrombomodulin Predicts Response to Steroid Therapy and Survival in Acute Intestinal Graft-Versus-Host Disease. Haematologica (2012) 97:1674-7. doi: 10.3324/haematol.2011.061051

30. Cordes S, Mokhtari Z, Bartosova M, Mertlitz S, Riesner K, Shi Y, et al. Endothelial Damage and Dysfunction in Acute Graft-Versus-Host Disease. Haematologica (2020), haematol.2020.253716. doi: 10.3324/ haematol.2020.253716

31. Bannerman DD, Goldblum SE. Mechanisms of Bacterial Lipopolysaccharide-Induced Endothelial Apoptosis. Am J Physiol Cell Mol Physiol (2003) 284:L899-914. doi: 10.1152/ajplung.00338.2002

32. Leonhardt F, Grundmann S, Behe M, Bluhm F, Dumont RA, Braun F, et al. Inflammatory Neovascularization During Graft-Versus-Host Disease is Regulated by $\alpha \mathrm{v}$ Integrin and Mir-100. Blood (2013) 121:3307-18. doi: 10.1182/blood-2012-07-442665

33. Penack O, Socié G, van den Brink MRM. The Importance of Neovascularization and its Inhibition for Allogeneic Hematopoietic Stem
Cell Transplantation. Blood (2011) 117:4181-9. doi: 10.1182/blood-201010-312934

34. Holtan SG, Verneris MR, Schultz KR, Newell LF, Meyers G, He F, et al. Circulating Angiogenic Factors Associated With Response and Survival in Patients With Acute Graft-Versus-Host Disease: Results From Blood and Marrow Transplant Clinical Trials Network 0302 and 0802. Biol Blood Marrow Transplant (2015) 21:1029-36. doi: 10.1016/j.bbmt.2015.02.018

35. Sackstein R. A Revision of Billingham's Tenets: The Central Role of Lymphocyte Migration in Acute Graft-Versus-Host Disease. Biol Blood Marrow Transplant (2006) 12:2-8. doi: 10.1016/j.bbmt.2005.09.015

36. Carreras E, Diaz-Ricart M. The Role of the Endothelium in the Short-Term Complications of Hematopoietic SCT. Bone Marrow Transplant (2011) 46:1495-502. doi: 10.1038/bmt.2011.65

37. Penack O, Henke E, Suh D, King CG, Smith OM, Na I-K, et al. Inhibition of Neovascularization to Simultaneously Ameliorate Graft-vs-Host Disease and Decrease Tumor Growth. JNCI J Natl Cancer Inst (2010) 102:894908. doi: 10.1093/jnci/djq172

38. Carreras E. Veno-Occlusive Disease of the Liver After Hemopoietic Cell Transplantation. Eur J Haematol (2000) 64:281-91. doi: 10.1034/j.16000609.2000.9r200.x

39. Roeker LE, Kim HT, Glotzbecker B, Nageshwar P, Nikiforow S, Koreth J, et al. Early Clinical Predictors of Hepatic Veno-Occlusive Disease/Sinusoidal Obstruction Syndrome After Myeloablative Stem Cell Transplantation. Biol Blood Marrow Transplant (2019) 25:137-44. doi: 10.1016/j.bbmt.2018.07.039

40. Mohty M, Malard F, Abecassis M, Aerts E, Alaskar AS, Aljurf M, et al. Sinusoidal Obstruction Syndrome/Veno-Occlusive Disease: Current Situation and Perspectives-a Position Statement From the European Society for Blood and Marrow Transplantation (Ebmt). Bone Marrow Transplant (2015) 50:781-9. doi: 10.1038/bmt.2015.52

41. Richardson PG, Carreras E, Iacobelli M, Nejadnik B. The Use of Defibrotide in Blood and Marrow Transplantation. Blood Adv (2018) 2:1495-509. doi: 10.1182/bloodadvances.2017008375

42. Palaniyandi S, Kumari R, Strattan E, Huang T, Du J, Kesler M, et al. Endothelial Protective Effects of Defibrotide Reduce Acute Graft Versus Host Disease After Experimental Allogeneic Hematopoietic Stem Cell Transplantation. Biol Blood Marrow Transplant (2020) 26:S52. doi: 10.1016/j.bbmt.2019.12.125

43. Palomo M, Diaz-Ricart M, Carreras E. Endothelial Dysfunction in Hematopoietic Cell Transplantation. Clin Hematol Int (2019) 1:45. doi: 10.2991/chi.d.190317.001

44. Arai Y, Yamashita K, Mizugishi K, Watanabe T, Sakamoto S, Kitano T, et al. Serum Neutrophil Extracellular Trap Levels Predict Thrombotic Microangiopathy After Allogeneic Stem Cell Transplantation. Biol Blood Marrow Transplant (2013) 19:1683-9. doi: 10.1016/j.bbmt.2013.09.005

45. Rosenthal J. Hematopoietic Cell Transplantation-Associated Thrombotic Microangiopathy: A Review of Pathophysiology, Diagnosis, and Treatment. J Blood Med (2016) 7:181-6. doi: 10.2147/JBM.S102235

46. Jodele S, Davies SM, Lane A, Khoury J, Dandoy C, Goebel J, et al. Diagnostic and Risk Criteria for HSCT-associated Thrombotic Microangiopathy: A Study in Children and Young Adults. Blood (2014) 124:645-53. doi: 10.1182/ blood-2014-03-564997

47. Ruutu T, Barosi G, Benjamin RJ, Clark RE, George JN, Gratwohl A, et al. Diagnostic Criteria for Hematopoietic Stem Cell Transplant-Associated Microangiopathy: Results of a Consensus Process by an International Working Group. Haematologica (2007) 92:95-100. doi: 10.3324/ haematol.10699

48. Ho VT, Cutler C, Carter S, Martin P, Adams R, Horowitz M, et al. Blood and Marrow Transplant Clinical Trials Network Toxicity Committee Consensus Summary: Thrombotic Microangiopathy After Hematopoietic Stem Cell Transplantation. Biol Blood Marrow Transplant (2005) 11:571-5. doi: 10.1016/j.bbmt.2005.06.001

49. Vion A-C, Rautou P-E, Durand F, Boulanger C, Valla D. Interplay of Inflammation and Endothelial Dysfunction in Bone Marrow Transplantation: Focus on Hepatic Veno-Occlusive Disease. Semin Thromb Hemost (2015) 41:629-43. doi: 10.1055/s-0035-1556728

50. Carreras E. How I Manage Sinusoidal Obstruction Syndrome After Haematopoietic Cell Transplantation. Br J Haematol (2015) 168:481-91. doi: $10.1111 /$ bjh.13215 
51. Mohty M, Malard F, Abecasis M, Aerts E, Alaskar AS, Aljurf M, et al. Prophylactic, Preemptive, and Curative Treatment for Sinusoidal Obstruction Syndrome/Veno-Occlusive Disease in Adult Patients: A Position Statement From an International Expert Group. Bone Marrow Transplant (2020) 55:485-95. doi: 10.1038/s41409-019-0705-z

52. Corbacioglu S, Carreras E, Ansari M, Balduzzi A, Cesaro S, Dalle J-H, et al. Diagnosis and Severity Criteria for Sinusoidal Obstruction Syndrome/VenoOcclusive Disease in Pediatric Patients: A New Classification From the European Society for Blood and Marrow Transplantation. Bone Marrow Transplant (2018) 53:138-45. doi: 10.1038/bmt.2017.161

53. Mohty M, Malard F, Abecassis M, Aerts E, Alaskar AS, Aljurf M, et al. Revised Diagnosis and Severity Criteria for Sinusoidal Obstruction Syndrome/Veno-Occlusive Disease in Adult Patients: A New Classification From the European Society for Blood and Marrow Transplantation. Bone Marrow Transplant (2016) 51:906-12. doi: 10.1038/bmt.2016.130

54. Zhang Y, Yan Y, Song B. Noninvasive Imaging Diagnosis of Sinusoidal Obstruction Syndrome: A Pictorial Review. Insights Imaging (2019) 10:110. doi: 10.1186/s13244-019-0791-x

55. Carreras E, Bertz H, Arcese W, Vernant JP, Tomás JF, Hagglund H, et al. Incidence and Outcome of Hepatic Veno-Occlusive Disease After Blood or Marrow Transplantation: A Prospective Cohort Study of the European Group for Blood and Marrow Transplantation. European Group for Blood and Marrow Transplantation Chronic Leukemia Work. Blood (1998) 92:3599-604.

56. Barker CC, Butzner JD, Anderson RA, Brant R, Sauve RS. Incidence, Survival and Risk Factors for the Development of Veno-Occlusive Disease in Pediatric Hematopoietic Stem Cell Transplant Recipients. Bone Marrow Transplant (2003) 32:79-87. doi: 10.1038/sj.bmt.1704069

57. Richardson PG, Soiffer RJ, Antin JH, Uno H, Jin Z, Kurtzberg J, et al. Defibrotide for the Treatment of Severe Hepatic Veno-Occlusive Disease and Multiorgan Failure After Stem Cell Transplantation: A Multicenter, Randomized, Dose-Finding Trial. Biol Blood Marrow Transplant (2010) 16:1005-17. doi: 10.1016/j.bbmt.2010.02.009

58. Corbacioglu S, Cesaro S, Faraci M, Valteau-Couanet D, Gruhn B, Rovelli A, et al. Defibrotide for Prophylaxis of Hepatic Veno-Occlusive Disease in Paediatric Haemopoietic Stem-Cell Transplantation: An Open-Label, Phase 3, Randomised Controlled Trial. Lancet (2012) 379:1301-9. doi: 10.1016/ S0140-6736(11)61938-7

59. Magenau JM, Goldstein SC, Peltier D, Soiffer RJ, Braun T, Pawarode A, et al.

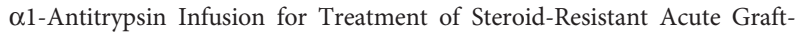
Versus-Host Disease. Blood (2018) 131:1372-9. doi: 10.1182/blood-2017-11815746

60. Dvorak CC, Higham C, Shimano KA. Transplant-Associated Thrombotic Microangiopathy in Pediatric Hematopoietic Cell Transplant Recipients: A Practical Approach to Diagnosis and Management. Front Pediatr (2019) 7:133. doi: $10.3389 /$ fped.2019.00133

61. Jiang S, Penack O, Terzer T, Schult D, Majer-Lauterbach J, Radujkovic A, et al. Predicting Sinusoidal Obstruction Syndrome After Allogeneic Stem Cell Transplantation With the EASIX Biomarker Panel. Haematologica (2020) 106:446-53. doi: 10.3324/haematol.2019.238790

62. Richard S, Seigneur M, Blann A, Adams R, Renard M, Puntous M, et al. Vascular Endothelial Lesion in Patients Undergoing Bone Marrow Transplantation. Bone Marrow Transplant (1996) 18:955-9.

63. Luft T, Dietrich S, Falk C, Conzelmann M, Hess M, Benner A, et al. SteroidRefractory GVHD: T-Cell Attack Within a Vulnerable Endothelial System. Blood (2011) 118:1685-92. doi: 10.1182/blood-2011-02-334821

64. Matsuda Y, Hara J, Osugi Y, Tokimasa S, Fujisaki H, Takai K, et al. Serum Levels of Soluble Adhesion Molecules in Stem Cell Transplantation-Related Complications. Bone Marrow Transplant (2001) 27:977-82. doi: 10.1038/ sj.bmt. 1703026

65. Cutler C, Kim HT, Ayanian S, Bradwin G, Revta C, Aldridge J, et al. Prediction of Veno-Occlusive Disease Using Biomarkers of Endothelial Injury. Biol Blood Marrow Transplant (2010) 16:1180-5. doi: 10.1016/ j.bbmt.2010.02.016

66. Akil A, Zhang Q, Mumaw CL, Raiker N, Yu J, Velez de Mendizabal N, et al. Biomarkers for Diagnosis and Prognosis of Sinusoidal Obstruction Syndrome After Hematopoietic Cell Transplantation. Biol Blood Marrow Transplant (2015) 21:1739-45. doi: 10.1016/j.bbmt.2015.07.004
67. Balakrishnan B, Illangeswaran RSS, Rajamani BM, Pai AA, Raj IX, Paul DZ, et al. Prognostic Plasma Biomarkers of Early Complications and GraftVersus-Host Disease in Patients Undergoing Allogeneic Hematopoietic Stem Cell Transplantation. eJHaem (2020) 1:219-29. doi: 10.1002/jha2.26

68. Catani L, Gugliotta L, Vianelli N, Nocentini F, Baravelli S, Bandini G, et al. Endothelium and Bone Marrow Transplantation. Bone Marrow Transplant (1996) 17:277-80.

69. Nakamura K, Hatano E, Miyagawa-Hayashino A, Okuno M, Koyama Y, Narita $M$, et al. Soluble Thrombomodulin Attenuates Sinusoidal Obstruction Syndrome in Rat Through Suppression of High Mobility Group Box 1. Liver Int (2014) 34:1473-87. doi: 10.1111/liv.12420

70. Zeigler ZR, Rosenfeld CS, Andrews DF, Nemunaitis J, Raymond JM, Shadduck RK, et al. Plasma Von Willebrand Factor Antigen (vWF : AG) and Thrombomodulin (TM) Levels in Adult Thrombotic Thrombocytopenic Purpura/Hemolytic Uremic Syndromes (TTP/HUS) and Bone Marrow Transplant-Associated Thrombotic Microangiopathy (BMT-TM). Am J Hematol (1996) 53:213-20. doi: 10.1002/(SICI)10968652(199612)53:4<213::AID-AJH1>3.0.CO;2-0

71. Ueda N, Chihara D, Kohno A, Tatekawa S, Ozeki K, Watamoto K, et al. Predictive Value of Circulating Angiopoietin-2 for Endothelial DamageRelated Complications in Allogeneic Hematopoietic Stem Cell Transplantation. Biol Blood Marrow Transplant (2014) 20:1335-40. doi: 10.1016/j.bbmt.2014.04.030

72. Nürnberger W, Michelmann I, Burdach S, Göbel U. Endothelial Dysfunction After Bone Marrow Transplantation: Increase of Soluble Thrombomodulin and PAI-1 in Patients With Multiple Transplant-Related Complications. Ann Hematol (1998) 76:61-5. doi: 10.1007/s002770050364

73. DeLeve LD, McCuskey RS, Wang X, Hu L, McCuskey MK, Epstein RB, et al. Characterization of a Reproducible Rat Model of Hepatic Veno-Occlusive Disease. Hepatology (1999) 29:1779-91. doi: 10.1002/hep.510290615

74. Moiseev IS, Lapin SV, Surkova EA, Lerner MY, Vavilov VN, Afanasyev BV. Level of Vascular Endothelial Growth Factor Predicts Both Relapse and Nonrelapse Mortality After Allogeneic Hematopoietic Stem Cell Transplantation. Biol Blood Marrow Transplant (2013) 19:1677-82. doi: 10.1016/j.bbmt.2013.08.015

75. Lunn RA, Sumar N, Bansal AS, Treleaven J. Cytokine Profiles in Stem Cell Transplantation: Possible Use as a Predictor of Graft-Versus-Host Disease. Hematology (2005) 10:107-14. doi: 10.1080/10245330400001975

76. Woywodt A, Haubitz M, Buchholz S, Hertenstein B. Counting the Cost: Markers of Endothelial Damage in Hematopoietic Stem Cell Transplantation. Bone Marrow Transplant (2004) 34:1015-23. doi: 10.1038/sj.bmt.1704733

77. Woywodt A, Scheer J, Hambach L, Buchholz S, Ganser A, Haller H, et al. Circulating Endothelial Cells as a Marker of Endothelial Damage in Allogeneic Hematopoietic Stem Cell Transplantation. Blood (2004) 103:3603-5. doi: 10.1182/blood-2003-10-3479

78. Almici C, Skert C, Bruno B, Bianchetti A, Verardi R, Di Palma A, et al. Circulating Endothelial Cell Count: A Reliable Marker of Endothelial Damage in Patients Undergoing Hematopoietic Stem Cell Transplantation. Bone Marrow Transplant (2017) 52:1637-42. doi: 10.1038/bmt.2017.194

79. Almici C, Neva A, Skert C, Bruno B, Verardi R, Di Palma A, et al. Counting Circulating Endothelial Cells in allo-HSCT: An Ad Hoc Designed Polychromatic Flowcytometry-Based Panel Versus the CellSearch System. Sci Rep (2019) 9:87. doi: 10.1038/s41598-018-36442-9

80. Burger D, Touyz RM. Cellular Biomarkers of Endothelial Health: Microparticles, Endothelial Progenitor Cells, and Circulating Endothelial Cells. J Am Soc Hypertens (2012) 6:85-99. doi: 10.1016/j.jash.2011.11.003

81. Pytlík R, Kideryová L, Benesová $K$, Cechová $H$, Veselá R, Rychtrmocová $H$, et al. Circulating Endothelial Precursor Cells (EPC) in Patients Undergoing Allogeneic Haematopoietic Progenitor Cell Transplantation. Folia Biol (Praha) (2010) 56:32-5.

82. Takeuchi M, Oda S, Tsuneyama K, Yokoi T. Comprehensive Analysis of Serum microRNAs in Hepatic Sinusoidal Obstruction Syndrome (SOS) in Rats: Implication as Early Phase Biomarkers for SOS. Arch Toxicol (2018) 92:2947-62. doi: 10.1007/s00204-018-2269-x

83. Wang L, Gu Z, Zhao X, Yang N, Wang F, Deng A, et al. Extracellular Vesicles Released From Human Umbilical Cord-Derived Mesenchymal Stromal Cells Prevent Life-Threatening Acute Graft-Versus-Host Disease in a Mouse 
Model of Allogeneic Hematopoietic Stem Cell Transplantation. Stem Cells $\operatorname{Dev}(2016)$ 25:1874-83. doi: 10.1089/scd.2016.0107

84. Lia G, Brunello L, Bruno S, Carpanetto A, Omedè P, Festuccia M, et al. Extracellular Vesicles as Potential Biomarkers of Acute Graft-vs-Host Disease. Leukemia (2018) 32:765-73. doi: 10.1038/leu.2017.277

85. Brunello L, Lia G, Bruno S, Tapparo M, Omede P, Festuccia M, et al. Biomarkers of Acute Graft-Versus-Host Disease: Surface Antigens and Micro Rnas in Extracellular Vesicles. Biol Blood Marrow Transplant (2019) 25:S232. doi: 10.1016/j.bbmt.2018.12.223

86. Luft T, Benner A, Jodele S, Dandoy CE, Storb R, Gooley T, et al. EASIX in Patients With Acute Graft-Versus-Host Disease: A Retrospective Cohort Analysis. Lancet Haematol (2017) 4:e414-23. doi: 10.1016/S2352-3026(17) 30108-4

87. Leonhardt F, Grundmann S, Behe M, Bluhm F, Dumont RA, Braun F, et al. Inflammatory Neovascularization During Graft-Versus-Host Disease is Regulated by V Integrin and Mir-100. Blood (2013) 121:3307-18. doi: 10.1182/blood-2012-07-442665

88. Gimondi S, Dugo M, Vendramin A, Bermema A, Biancon G, Cavané A, et al. Circulating miRNA Panel for Prediction of Acute Graft-Versus-Host Disease in Lymphoma Patients Undergoing Matched Unrelated Hematopoietic Stem Cell Transplantation. Exp Hematol (2016) 44:624-34. doi: $10.1016 /$ j.exphem.2016.03.005

89. Sang W, Zhang C, Zhang D, Wang Y, Sun C, Niu M, et al. MicroRNA-181a, a Potential Diagnosis Marker, Alleviates Acute Graft Versus Host Disease by Regulating IFN- $\gamma$ Production. Am J Hematol (2015) 90:998-1007. doi: 10.1002/ajh.24136

90. Koenecke C, Krueger A. MicroRNA in T-Cell Development and T-Cell Mediated Acute Graft-Versus-Host Disease. Front Immunol (2018) 9:992. doi: 10.3389/fimmu.2018.00992

91. Crossland RE, Norden J, Juric MK, Green K, Pearce KF, Lendrem C, et al. Expression of Serum microRNAs is Altered During Acute Graft-Versus-Host Disease. Front Immunol (2017) 8:308. doi: 10.3389/fimmu.2017.00308

92. Yamamoto S, Niida S, Azuma E, Yanagibashi T, Muramatsu M, Huang TT, et al. Inflammation-Induced Endothelial Cell-Derived Extracellular Vesicles Modulate the Cellular Status of Pericytes. Sci Rep (2015) 5:8505. doi: 10.1038/srep08505

93. Levine JE, Braun TM, Harris AC, Holler E, Taylor A, Miller H, et al. A Prognostic Score for Acute Graft-Versus-Host Disease Based on Biomarkers: A Multicentre Study. Lancet Haematol (2015) 2:e21-9. doi: 10.1016/S23523026(14)00035-0

94. McDonald GB, Tabellini L, Storer BE, Lawler RL, Martin PJ, Hansen JA. Plasma Biomarkers of Acute GVHD and Nonrelapse Mortality: Predictive Value of Measurements Before GVHD Onset and Treatment. Blood (2015) 126:113-20. doi: 10.1182/blood-2015-03-636753

95. Foley R, Couban S, Walker I, Greene K, Chen CS, Messner H, et al. Monitoring Soluble Interleukin-2 Receptor Levels in Related and Unrelated Donor Allogenic Bone Marrow Transplantation. Bone Marrow Transplant (1998) 21:769-73. doi: 10.1038/sj.bmt.1701163

96. Ponce DM, Hilden P, Mumaw C, Devlin SM, Lubin M, Giralt S, et al. High Day 28 ST2 Levels Predict for Acute Graft-Versus-Host Disease and Transplant-Related Mortality After Cord Blood Transplantation. Blood (2015) 125:199-205. doi: 10.1182/blood-2014-06-584789

97. Vander Lugt MT, Braun TM, Hanash S, Ritz J, Ho VT, Antin JH, et al. ST2 as a Marker for Risk of Therapy-Resistant Graft-Versus-Host Disease and Death. N Engl J Med (2013) 369:529-39. doi: 10.1056/NEJMoa1213299

98. Hartwell MJ, Özbek U, Holler E, Renteria AS, Major-Monfried H, Reddy P, et al. An Early-Biomarker Algorithm Predicts Lethal Graft-Versus-Host Disease and Survival. JCI Insight (2017) 2:e89798. doi: 10.1172/ jci.insight. 89798

99. Srinagesh HK, Ferrara JLM. MAGIC Biomarkers of Acute Graft-VersusHost Disease: Biology and Clinical Application. Best Pract Res Clin Haematol (2019) 32:101111. doi: 10.1016/j.beha.2019.101111

100. Solán L, Kwon M, Carbonell D, Dorado N, Balsalobre P, Serrano D, et al. ST2 and REG3 $\alpha$ as Predictive Biomarkers After Haploidentical Stem Cell Transplantation Using Post-transplantation High-Dose Cyclophosphamide. Front Immunol (2019) 10:2338. doi: 10.3389/fimmu.2019.02338

101. Abu Zaid M, Wu J, Wu C, Logan BR, Yu J, Cutler C, et al. Plasma Biomarkers of Risk for Death in a Multicenter Phase 3 Trial With Uniform Transplant
Characteristics Post-Allogeneic HCT. Blood (2017) 129:162-70. doi: 10.1182/blood-2016-08-735324

102. Zeiser R, Blazar BR. Acute Graft-versus-Host Disease - Biologic Process, Prevention, and Therapy. N Engl J Med (2017) 377:2167-79. doi: 10.1056/ NEJMra1609337

103. Ali AM, DiPersio JF, Schroeder MA. The Role of Biomarkers in the Diagnosis and Risk Stratification of Acute Graft-versus-Host Disease: A Systematic Review. Biol Blood Marrow Transplant (2016) 22:1552-64. doi: 10.1016/j.bbmt.2016.04.022

104. Schuh MP, Bennett MR, Lane A, Jodele S, Laskin BL, Devarajan P. Haptoglobin Degradation Product as a Novel Serum Biomarker for Hematopoietic Stem Cell Transplant-Associated Thrombotic Microangiopathy. Pediatr Nephrol (2019) 34:865-71. doi: 10.1007/s00467-018-4178-x

105. Luft T, Benner A, Terzer T, Jodele S, Dandoy CE, Storb R, et al. EASIX and Mortality After Allogeneic Stem Cell Transplantation. Bone Marrow Transplant (2020) 55:553-61. doi: 10.1038/s41409-019-0703-1

106. Sebghati ZJ, Abbasi S, Abhyankar S, Ganguly S, Shune L, McGuirk JP, et al. Endothelial Activation and Stress Index (Easix) Score at 100 Days Post-Allo HCT in Patients With Acute Myeloid Leukemia Predicts Overall Survival. Biol Blood Marrow Transplant (2020) 26:S121. doi: 10.1016/j.bbmt.2019.12.634

107. Gavriilaki E, Sakellari I, Chatziconstantinou T, Mallouri D, Batsis I, Vardi A, et al. Easix Is Strongly Associated With Complement Activation and Overall Survival in Adult Allogeneic Hematopoietic Cell Transplantation Recipients. Blood (2019) 134:4520-0. doi: 10.1182/blood-2019-125332

108. Srinagesh HK, Özbek U, Kapoor U, Ayuk F, Aziz M, Ben-David K, et al. The MAGIC Algorithm Probability is a Validated Response Biomarker of Treatment of Acute Graft-Versus-Host Disease. Blood Adv (2019) 3:403442. doi: 10.1182/bloodadvances.2019000791

109. Moscardó F, Urbano-Ispizua A, Sanz GF, Brunet S, Caballero D, Vallejo C, et al. Positive Selection for CD34+ Reduces the Incidence and Severity of Veno-Occlusive Disease of the Liver After HLA-identical Sibling Allogeneic Peripheral Blood Stem Cell Transplantation. Exp Hematol (2003) 31:545-50. doi: 10.1016/S0301-472X(03)00070-5

110. Erdbruegger U, Dhaygude A, Haubitz M, Woywodt A. Circulating Endothelial Cells: Markers and Mediators of Vascular Damage. Curr Stem Cell Res Ther (2010) 5:294-302. doi: 10.2174/157488810793351721

111. Zonneveld R, Martinelli R, Shapiro NI, Kuijpers TW, Plötz FB, Carman CV. Soluble Adhesion Molecules as Markers for Sepsis and the Potential Pathophysiological Discrepancy in Neonates, Children and Adults. Crit Care (2014) 18:204. doi: 10.1186/cc13733

112. Nomura S, Ishii K, Fujita S, Nakaya A, Satake A, Ito T. Associations Between Acute GVHD-related Biomarkers and Endothelial Cell Activation After Allogeneic Hematopoietic Stem Cell Transplantation. Transpl Immunol (2017) 43-44:27-32. doi: 10.1016/j.trim.2017.06.004

113. Chen Y-B, Cutler CS. Biomarkers for Acute GVHD: can We Predict the Unpredictable? Bone Marrow Transplant (2013) 48:755-60. doi: 10.1038/ bmt.2012.143

114. Choi SW, Kitko CL, Braun T, Paczesny S, Yanik G, Mineishi S, et al. Change in Plasma Tumor Necrosis Factor Receptor 1 Levels in the First Week After Myeloablative Allogeneic Transplantation Correlates With Severity and Incidence of GVHD and Survival. Blood (2008) 112:1539-42. doi: 10.1182/ blood-2008-02-138867

115. Hill GR, Teshima T, Rebel VI, Krijanovski OI, Cooke KR, Brinson YS, et al. The P55 TNF-alpha Receptor Plays a Critical Role in T Cell Alloreactivity. J Immunol (2000) 164:656-63. doi: 10.4049/jimmunol.164.2.656

116. Kaida K, Ikegame K, Fujioka T, Taniguchi Y, Yoshihara S, Kawakami M, et al. Serum Levels of Soluble Interleukin-2 Receptor is a Powerful Marker of Acute Graft-Versus Host Disease After HLA-haploidentical Bone Marrow Transplantation. Biol Blood Marrow Transplant (2006) 12:66-7. doi: 10.1016/j.bbmt.2005.11.209

117. Miyamoto T, Akashi K, Hayashi S, Gondo H, Murakawa M, Tanimoto K, et al. Serum Concentration of the Soluble Interleukin-2 Receptor for Monitoring Acute Graft-Versus-Host Disease. Bone Marrow Transplant (1996) 17:185-90.

118. Nakamura Y, Tanaka Y, Tanaka M, Sugiyama A, Yamamoto K, Tokunaga Y, et al. Soluble Interleukin-2 Receptor Index Predicts the Development of Acute Graft-Versus-Host Disease After Allogeneic Hematopoietic Stem Cell Transplantation From Unrelated Donors. Int J Hematol (2016) 103:436-43. doi: $10.1007 / \mathrm{s} 12185-016-1936-\mathrm{z}$ 
119. AbouEzzeddine OF, McKie PM, Dunlay SM, Stevens SR, Felker GM, Borlaug BA, et al. Soluble ST2 in Heart Failure With Preserved Ejection Fraction. $J$ Am Heart Assoc (2017) 6. doi: 10.1161/JAHA.116.004382

120. Demyanets S, Konya V, Kastl SP, Kaun C, Rauscher S, Niessner A, et al. Interleukin-33 Induces Expression of Adhesion Molecules and Inflammatory Activation in Human Endothelial Cells and in Human Atherosclerotic Plaques. Arterioscler Thromb Vasc Biol (2011) 31:2080-9. doi: 10.1161/ ATVBAHA.111.231431

121. Griesenauer B, Paczesny S. The ST2/IL-33 Axis in Immune Cells During Inflammatory Diseases. Front Immunol (2017) 8:475. doi: 10.3389/ fimmu.2017.00475

122. Ferrara JLM, Harris AC, Greenson JK, Braun TM, Holler E, Teshima T, et al. Regenerating Islet-Derived 3-Alpha is a Biomarker of Gastrointestinal GraftVersus-Host Disease. Blood (2011) 118:6702-8. doi: 10.1182/blood-2011-08375006

123. Farinacci M, Krahn T, Dinh W, Volk H-D, Düngen H-D, Wagner J, et al. Circulating Endothelial Cells as Biomarker for Cardiovascular Diseases. Res Pract Thromb Haemost (2019) 3:49-58. doi: 10.1002/rth2.12158

124. Sabatier F, Camoin-Jau L, Anfosso F, Sampol J, Dignat-George F. Circulating Endothelial Cells, Microparticles and Progenitors: Key Players Towards the Definition of Vascular Competence. J Cell Mol Med (2009) 13:454-71. doi: $10.1111 / j .1582-4934.2008 .00639 . x$

125. Flores-Nascimento MC, Alessio AM, de Andrade Orsi FL, Annichino-Bizzacchi JM. Cd144, CD146 and VEGFR-2 Properly Identify Circulating Endothelial Cell. Rev Bras Hematol Hemoter (2015) 37:98-102. doi: 10.1016/j.bjhh.2014.11.014

126. Condrat CE, Thompson DC, Barbu MG, Bugnar OL, Boboc A, Cretoiu D, et al. miRNAs as Biomarkers in Disease: Latest Findings Regarding Their Role in Diagnosis and Prognosis. Cells (2020) 9:276. doi: 10.3390/cells9020276

127. Ranganathan P, Heaphy CEA, Costinean S, Stauffer N, Na C, Hamadani M, et al. Regulation of Acute Graft-Versus-Host Disease by Microrna-155. Blood (2012) 119:4786-97. doi: 10.1182/blood-2011-10-387522

128. Maas SLN, Breakefield XO, Weaver AM. Extracellular Vesicles: Unique Intercellular Delivery Vehicles. Trends Cell Biol (2017) 27:172-88. doi: 10.1016/j.tcb.2016.11.003

129. Shah R, Patel T, Freedman JE. Circulating Extracellular Vesicles in Human Disease. N Engl J Med (2018) 379:958-66. doi: 10.1056/NEJMra1704286

130. Margolis L, Sadovsky Y. The Biology of Extracellular Vesicles: The Known Unknowns. PloS Biol (2019) 17:e3000363. doi: 10.1371/journal.pbio.3000363

131. Kaur S, Abu-Shahba AG, Paananen RO, Hongisto H, Hiidenmaa H, Skottman H, et al. Small non-Coding RNA Landscape of Extracellular Vesicles From Human Stem Cells. Sci Rep (2018) 8:15503. doi: 10.1038/ s41598-018-33899-6

132. Baglio SR, Rooijers K, Koppers-Lalic D, Verweij FJ, Pérez Lanzón M, Zini N, et al. Human Bone Marrow- and Adipose-Mesenchymal Stem Cells Secrete Exosomes Enriched in Distinctive miRNA and tRNA Species. Stem Cell Res Ther (2015) 6:127. doi: 10.1186/s13287-015-0116-z

133. Tramontano AF, Lyubarova R, Tsiakos J, Palaia T, DeLeon JR, Ragolia L. Circulating Endothelial Microparticles in Diabetes Mellitus. Mediators Inflammation (2010) 2010:1-8. doi: 10.1155/2010/250476

134. Jansen F, Yang X, Franklin BS, Hoelscher M, Schmitz T, Bedorf J, et al. High Glucose Condition Increases NADPH Oxidase Activity in Endothelial Microparticles That Promote Vascular Inflammation. Cardiovasc Res (2013) 98:94-106. doi: 10.1093/cvr/cvt013

135. Dignat-George F, Boulanger CM. The Many Faces of Endothelial Microparticles. Arterioscler Thromb Vasc Biol (2011) 31:27-33. doi: 10.1161/ATVBAHA.110.218123
136. Markiewicz M, Richard E, Marks N, Ludwicka-Bradley A. Impact of Endothelial Microparticles on Coagulation, Inflammation, and Angiogenesis in Age-Related Vascular Diseases. J Aging Res (2013) 2013:1-11. doi: 10.1155/2013/734509

137. Combes V, Simon A-C, Grau G-E, Arnoux D, Camoin L, Sabatier F, et al. In Vitro Generation of Endothelial Microparticles and Possible Prothrombotic Activity in Patients With Lupus Anticoagulant. J Clin Invest (1999) 104:93102. doi: $10.1172 /$ JCI 4985

138. Nomura $\mathrm{S}$, Ishii $\mathrm{K}$, Inami $\mathrm{N}$, Kimura $\mathrm{Y}$, Uoshima $\mathrm{N}$, Ishida $\mathrm{H}$, et al. Evaluation of Angiopoietins and Cell-Derived Microparticles After Stem Cell Transplantation. Biol Blood Marrow Transplant (2008) 14:766-74. doi: 10.1016/j.bbmt.2008.04.005

139. Liu Y, Huang W, Zhang R, Wu J, Li L, Tang Y. Proteomic Analysis of TNF$\alpha$-Activated Endothelial Cells and Endothelial Microparticles. Mol Med Rep (2013) 7:318-26. doi: 10.3892/mmr.2012.1139

140. Huang P-H, Huang S-S, Chen Y-H, Lin C-P, Chiang K-H, Chen J-S, et al. Increased Circulating CD31+/annexin V+ Apoptotic Microparticles and Decreased Circulating Endothelial Progenitor Cell Levels in Hypertensive Patients With Microalbuminuria. J Hypertens (2010) 28:1655-65. doi: 10.1097/HJH.0b013e32833a4d0a

141. Sinning J-M, Losch J, Walenta K, Bohm M, Nickenig G, Werner N. Circulating CD31+/Annexin V+ Microparticles Correlate With Cardiovascular Outcomes. Eur Heart J (2011) 32:2034-41. doi: 10.1093/ eurheartj/ehq478

142. Berezin AE, Kremzer AA, Berezina TA, Martovitskaya YV. Pattern of Circulating Microparticles in Chronic Heart Failure Patients With Metabolic Syndrome: Relevance to Neurohumoral and Inflammatory Activation. BBA Clin (2015) 4:69-75. doi: 10.1016/j.bbacli.2015.07.002

143. Jimenez JJ, Jy W, Mauro LM, Soderland C, Horstman LL, Ahn YS. Endothelial Cells Release Phenotypically and Quantitatively Distinct Microparticles in Activation and Apoptosis. Thromb Res (2003) 109:17580. doi: 10.1016/s0049-3848(03)00064-1

144. Jimenez JJ, Jy W, Mauro LM, Horstman LL, Soderland C, Ahn YS. Endothelial Microparticles Released in Thrombotic Thrombocytopenic Purpura Express Von Willebrand Factor and Markers of Endothelial Activation. Br J Haematol (2003) 123:896-902. doi: 10.1046/j.13652141.2003.04716.x

145. Piccin A, Sartori MT, Bisogno G, Van Schilfgaarde M, Saggiorato G, Pierro AMD, et al. New Insights Into Sinusoidal Obstruction Syndrome. Intern Med $J$ (2017) 47:1173-83. doi: 10.1111/imj.13550

146. Zhang R, Wang X, Hong M, Luo T, Zhao M, Shen H, et al. Endothelial Microparticles Delivering microRNA-155 Into T Lymphocytes are Involved in the Initiation of Acute Graft-Versus-Host Disease Following Allogeneic Hematopoietic Stem Cell Transplantation. Oncotarget (2017) 8:23360-75. doi: 10.18632/oncotarget.15579

Conflict of Interest: The authors declare that the research was conducted in the absence of any commercial or financial relationships that could be construed as a potential conflict of interest.

Copyright (c) 2021 Lia, Giaccone, Leone and Bruno. This is an open-access article distributed under the terms of the Creative Commons Attribution License (CC BY). The use, distribution or reproduction in other forums is permitted, provided the original author(s) and the copyright owner(s) are credited and that the original publication in this journal is cited, in accordance with accepted academic practice. No use, distribution or reproduction is permitted which does not comply with these terms. 